\title{
A EXPERIENCIA LÚDICA EM FORMA DE IMAGENS: O PROTAGONISMO DAS CRIANÇAS NO PROCESSO DE COLETA DE DADOS
}

\author{
Nair Correia Salgado de Azevedo ${ }^{1}$, José Milton de Lima ${ }^{2}$ \\ 1,2 Universidade Estadual Paulista - UNESP, Programa de Pós-graduação em Educação, Presidente Prudente, SP. \\ ${ }^{1}$ Universidade do Oeste Paulista - UNOESTE, curso de Pedagogia, Presidente Prudente, SP. Email: \\ miltonlima@fct.unesp.br
}

\section{RESUMO}

Esse trabalho é fruto de uma pesquisa de doutorado que se propõe a apresentar como as práticas lúdicas podem contribuir para o processo de ensino e aprendizagem das crianças no contexto escolar. Para isso, essa pesquisa do tipo etnográfico e de caráter qualitativo se propôs a ouvir cerca de cinquenta crianças que estudavam entre o quarto e quinto anos do ensino fundamental tentando perceber o que elas tinham a dizer sobre a importância da ludicidade na escola. Foram utilizados instrumentos variados para a coleta dessas informações, como as fotos, o diário de bordo, o diário coletivo, o texto ilustrado, as entrevistas-conversas e, dentre elas, a que mais discutiremos nesse trabalho, que são as filmagens feitas pelas próprias crianças. Realizada de uma forma menos convencional, as filmagens se mostraram uma importante aliada para que pudéssemos perceber que muitas práticas lúdicas consideradas importantes pelas crianças aconteciam fora do contexto de sala de aula e, quando estas aconteciam na sala de aula, demonstravam que as crianças consideram importante a prática pedagógica diferenciada do professor.

Palavras-chave: infância; ludicidade; etnografia; filmagem; significados

\section{THE PALYFUL EXPERIENCE IN PICTURES DESIGN: THE LEADERSHIP OF CHILDREN IN THE PROCESS OF DATA COLLECTION}

\begin{abstract}
This work is the result of a doctoral research aims to present how the playful practices can contribute to the teaching and learning of children in the school context. For this, the survey of ethnographic and qualitative set out to hear about fifty children studied between the fourth and fifth years of elementary school trying to figure out what they had to say about the importance of playfulness in school. Various instruments were used to collect this information, such as photos, logbook, the collective diary, illustrated text, interviews, conversations and, among them, the more we discuss this work, which are the films made by their own children. Performed in a less conventional way, filming proved an important ally that we might realize that many playful practices considered important for children took place outside the classroom context and, when they happened in the classroom, showed that children consider important differentiated teacher's pedagogic practice.
\end{abstract}

Keywords: Childhood ; playfulness ; ethnography ; shooting; meanings 


\section{INTRODUÇÃO}

Entendemos que o termo "paradigma", no sentido de crer que determinada forma de ver, analisar e interpretar os processos educacionais possui um caminho já trilhado e, portanto, digno de ser seguido, ainda se faz presente em algumas pesquisas educacionais acadêmicas. Principalmente quando os envolvidos são crianças, vemos que o termo "paradigma" significa, muitas vezes, apenas observar as crianças sem, no entanto, tentar fazer com que elas expressem mais suas opiniões. Muitos autores como Corsaro (2011), Sarmento (2011), Martins Filho (2011), Delgado e Mülher (2009) nos tem alertado sobre a importância de se romper com velhos paradigmas para que possamos considerar a real visão e voz das crianças.

Portanto, é preciso que o pesquisador tenha em mente que é preciso descobrir, entre as possibilidades que nos são dadas pelas crianças, uma nova forma de pesquisar, "principalmente no intuito de inventar, criar e estabelecer outras formas de comunicação com elas, o que coincidirá com a criação de outros procedimentos teórico-metodológicos de pesquisa" (MARTINS FILHO, 2011, p. 96).

Por todas essas razões é que a pesquisa qualitativa, do tipo etnográfico, tem sido elencada por vários pesquisadores como a forma mais adequada de se realizar pesquisas com crianças. Características como a flexibilidade de técnicas, a possibilidade de adentrar o mundo pesquisado de forma engajada e prolongada faz da etnografia uma pesquisa bastante adequada quando os sujeitos são crianças.

\section{METODOLOGIA, LÓCUS E SUJEITOS DA PESQUISA}

Essa pesquisa passou pelo Comitê de Ética e Pesquisa da Faculdade de Ciências e Tecnologia - UNESP/Campus de Presidente Prudente, aprovada sob o protocolo de número 736.447 com data de 01/08/2014. Do tipo etnográfica, de caráter qualitativo, foi realizada em uma unidade de educação pública municipal do ensino fundamental, no município de Presidente Prudente - SP. A unidade escolar atende crianças da Educação Infantil ao 5o ano do Ensino Fundamental, totalizando aproximadamente 375 alunos. Fica localizada na periferia da região oeste do município de Presidente Prudente - SP.

Os dados foram coletados em duas turmas do $4 \% / 5 \%$ anos, no período de agosto a novembro de 2014 e março a agosto de 2015, com o mesmo grupo, totalizando 50 crianças no total. A pesquisa ocorreu durante vários momentos que, supostamente, são considerados como facilitadores para que ocorra a presença da ludicidade no ambiente escolar. Para identificar quais seriam esses momentos facilitadores do lúdico na escola, a priori, conversamos com as crianças 
sobre o que eles mais gostam na escola como um todo, podendo ser atividades dentro ou fora da sala de aula (como passeios, por exemplo) e, ainda, dentro ou fora do turno regular já que algumas crianças que participaram desse estudo permanecem na escola em tempo integral ${ }^{1}$.

Foram utilizados vários instrumentos para a coleta de dados, como a observação e as anotações do diário de campo, as entrevistas coletivas, os desenhos, o diário coletivo de brincadeiras e os textos ilustrados. Nesse artigo, daremos ênfase às filmagens realizadas pelas crianças durante o processo de coleta de dados.

A forma como esse instrumento foi utilizado nessa pesquisa pode ser considerado bastante peculiar daquela que a maioria dos estudos acadêmicos para e com a infância sugerem, pois geralmente a filmagem é realizada pelo pesquisador com o intuito de captar mais detalhadamente o contexto pesquisado. No caso desse estudo, as filmagens foram realizadas pelas crianças, e não pelo pesquisador.

Nesse sentido, o trabalho realizado pelo professor César Leite na Universidade Estadual Paulista/UNESP - Campus de Rio Claro/SP, intitulado "Ação, câmera e luz: entre imagens e olhares", que consiste em valorizar o protagonismo infantil das crianças na produção de imagens, tem se tornado um referencial para pesquisadores de estudos para e com a infância que pretendem utilizar esse método. O referido trabalho é realizado com crianças de 8 a 11 anos em escolas públicas da cidade de Rio Claro/SP que filmam o que querem, sem instruções muito complexas, e o resultado foi bastante interessante: uma mudança radical de enfoque.

Quando você vai pra um trabalho em que se entrega a câmera na mão da criança, você não sabe como vai sair da pesquisa, não sabe o que ela vai te apresentar. Fazer pesquisa com crianças quando elas produzem as imagens é mudar radicalmente o protagonismo da cena. Porque não é mais o adulto aquele que olha e produz.

(...) Quando a gente pensa na criança com outro protagonismo, não podemos pensar em produção feita somente para a criança, mas também é preciso pensar em produções feitas 'pela' criança e 'com' a criança. É uma mudança radical de enfoque (LEITE; C., 2014, p.2).

O olhar do pesquisador, ao interpretar tais dados oferecidos pelas crianças, precisa estar atento àquilo que passa despercebido no cotidiano da pesquisa. "Oferecer câmeras fotográficas e filmadoras às crianças é se apresentar ao risco de caminhos por olhares desfocados, miradas longas, caminhos que insistem em mostrar atalhos, pés, chão" (LEITE, 2011, p. 125). No início, ao assistir as filmagens realizadas pelas crianças, as corridas ofegantes, o chão em movimento, os

\footnotetext{
${ }^{1}$ Entre as crianças que participam desse estudo cerca de metade delas participam, no período oposto ao das aulas regulares, das oficinas do Programa Municipal de Educação Integral "Cidadescola". As demais crianças frequentam a escola apenas no período da manhã onde se encaixam as aulas do período regular de sala de aula.
} 
gritos e toda aquela algazarra nos deixavam confusos. Tivemos que treinar nosso olhar para perceber que, mais que simplesmente os pés das crianças, o que apareciam nas filmagens eram ações dotadas de significados e que, só percebemos após uma reflexão sobre as filmagens e as conversas que tínhamos com as crianças sobre o que elas filmavam. É a necessidade de se ouvir aquilo que não é verbal (SARMENTO, 2011).

Durante esse estudo as crianças puderam optar por tirar fotos ou filmar as ações. Embora a grande maioria optasse por filmar as ações, houve crianças que optaram por fotografar e realizar muitas selfies. Para que não viéssemos a interpretar esses "textos imagéticos" (GOBBI, 2011) de forma equivocada, foi preciso usar de outra habilidade bem pessoal: a conversa com as crianças. É possível, partindo das expressões imagéticas, conversar com as crianças e a partir daí conjugar as imagens fotográficas a outros tipos de linguagem considerando o contexto da ação. "Investigar a percepção e a recepção das fotografias em diferentes contextos, bem como as próprias imagens nelas contidas e as condições culturais, sociais e econômicas que envolvem sua produção é imprescindível" (GOBBI, 2011, p. 143).

\section{Entre flashes, selfies e ações: quando é preciso retomar a claquete para rever alguns planos e tomadas da produção}

O início das filmagens contou com alguns eventos interessantes de serem mencionados nesse momento. A instrução sobre o manuseio do equipamento utilizado para as gravações de vídeos que, em grande maioria, como já mencionado, foi realizado pelas próprias crianças, será um dos primeiros a serem destacados. Além de ensinar às crianças como ligar, prender a câmera nas mãos, como trocar o modo filmagem pelo modo fotografia e demais regras como, por exemplo, elencar uma das crianças para que seja responsável pela filmagem (que poderia ser compartilhada ou não ${ }^{2}$ ), houve a necessidade de explicar a importância social da câmera para a pesquisa, pois no início as crianças ficaram receosas com relação ao que iriam filmar.

Um dos motivos que causou, num primeiro momento, esse receio, pode ser observado claramente na filmagem realizada por "Ski Safari" ${ }^{3}$, quando ele próprio diz "tudo o que a gente fala vai ficar gravado aqui, viu?" (Filmagem dirigida por "Ski Safari", 14/08/2014) e, ainda, quando

\footnotetext{
${ }^{2}$ A filmagem compartilhada foi uma ideia que surgiu durante as primeiras conversas com as crianças em que foi explicado como seria o procedimento de filmagem feito por elas. As crianças tiveram algumas curiosidades, entre elas, se poderiam passar a câmera para as mãos de um colega caso quisessem. Achei oportuno e de bom senso deixar as crianças livres para tomarem essa decisão, e combinamos então que a criança sorteada ficaria responsável pela filmagem, mas não precisaria obrigatoriamente ser a única a filmar.

${ }^{3}$ Uma das primeiras ações com as crianças foi de conscientizá-las sobre a importância do anonimato durante todo o processo de pesquisa. Explicamos a elas que era necessário pensarem em um nome diferente do nome real, para que eles não pudessem ser identificados. Após o esclarecimento de algumas dúvidas das crianças, como por exemplo, se poderiam usar nomes de personagens, artistas ou outro nome comum, cada criança escolheu seu nome fictício.
} 
"Ski Safari" resolve compartilhar a filmagem com o colega "Anderson", percebemos, mesmo que de forma inconsciente, uma atmosfera de vigilância às crianças:

Na quadra algumas crianças correm, outras giram, outras apenas conversam... As duas turmas de 40 anos estão na quadra. "Ski Safari" pergunta a "Anderson" se ele quer filmar e explica ao colega como manusear a câmera. "Anderson" chega mais perto para filmar melhor seus colegas.

Nesse momento, uma funcionária da escola passa, vê "Anderson" filmando e diz: "Gostei disso aí. Se você ver alguém batendo em alguém você filma, aí tem como provar 'Ó: foi fulano que bateu em ciclano'". "Anderson" responde: "Tá!". (Filmagem dirigida por "Ski Safari", 14/08/2014).

Foi preciso esclarecer no dia seguinte a esse incidente que não era objetivo da câmera vigiar o que eles estavam fazendo de "errado" ou não e que eles estavam apenas nos ajudando a compreender como se dá a experiência de brincar, de se inteirar sobre como isso ocorre dentro da escola e quais sentidos eles atribuem a isso. Explicamos que eles não precisavam ter medo do que fica registrado nas gravações e que as filmagens são realizadas com objetivo diferente de vigiar:

Conversei com eles a respeito do ocorrido ontem durante a filmagem feita por "Ski Safari", quando uma funcionária alertou que, a câmera era ótima para "vigiar" o que eles estavam fazendo de "errado". Esclareci que não é esse o objetivo da pesquisa: ver o que ocorre de "certo" ou "errado" enquanto eles brincam, e, ainda, que eu não iria mostrar a filmagem para ninguém além deles mesmos e que se fosse realmente necessário "vigiá-los" a escola estaria cheia de câmeras.

Nesse momento, "Percy Jackson", que foi o responsável pela filmagem no dia de hoje, me perguntou: "Nair, e se sair uma briga mesmo o que acontece? Eu paro de filmar?".

Respondi que o fato de filmar ou não uma briga não seria eu quem decidiria isso e sim a criança que estivesse responsável pela filmagem naquele dia. Também salientei que pode sim acontecer de, durante alguma filmagem, ocorrer uma briga em que houvesse, talvez, até a necessidade da intervenção de um adulto, mas que eu também gostaria de saber como as crianças resolveriam esses conflitos (Diário de bordo, 15/08/2014).

Nas filmagens que se sucederam após esse episódio, as crianças foram, aos poucos, deixando de ver a câmera como um objeto de vigilância, passando a vê-la com mais curiosidade. Isso é percebido em muitas filmagens após esse acontecimento em que aparecem crianças fazendo caretas, sorrindo, dando tchauzinho. Algumas crianças no início também se sentiram constrangidas ou surpresas com a gravação:

"Bart Simpson" reassume a filmagem e brinca de filmar seus colegas. As crianças se aglomeram à frente da câmera, umas entram na frente da outra enquanto outras conversam com "Bart Simpson" sobre a câmera. (Filmagem dirigida por "Bart Simpson", 22/08/2014)

É momento do recreio e "Thalia" filma "Homem Aranha" que toca escaleta, sem que ele perceba. Assim que percebe a gravação, leva um susto e todos dão muitas risadas. (Filmagem dirigida por "Thalia", 25/08/2014). 
Graue e Walsh (2003) também experienciaram a utilização da filmagem de vídeo em seus estudos, e argumentam que há sim muitas vantagens nessa técnica, como o registro das expressões faciais das crianças, por exemplo, mas destacam como desvantagem a falta de discrição. Apesar de as câmeras de hoje em dia serem bem mais discretas que as descritas pelos autores (grandes e com tripés chamativos), nesse caso pudemos perceber que a indiscrição gerada pela câmera foi em outro sentido: no de vigiar, fiscalizar.

Para evitar esse constrangimento, a estratégia utilizada por esse estudo foi a de conversar com as crianças sobre o ocorrido. Como bem argumenta Martins Filho (2011), o pesquisador, ao escolher as técnicas de coleta de dados com as crianças, precisa estreitar cada vez mais os laços com elas, favorecendo as relações e o desenvolvimento de uma participação sensível às produções das crianças.

Dessa forma, a descobertas das cenas flagradas pelas câmeras, sejam através de fotos ou filmagens, revelam o cotidiano das crianças. Trata-se de um cenário que temos que descobrir, pois são marcas históricas deixadas por todos.

Descortina-se um cenário diante de nós como pistas a serem seguidas. Imagens cujas presenças podem ficar retidas na retina, no corpo, nos diversos espaços frequentados pelos meninos e meninas. Ela informa, indubitavelmente, mas o denotado pode ser interpretado, lido, questionado nas mais diferentes vertentes, estabelece e faz estabelecer relações sociais no lugar em que ocupa (GOBBI, 2011, p. 144).

Mãos que desenham e escrevem, corpos que correm e filmam ao mesmo tempo, bocas que falam e sorriem, rostos que fazem caretas e imitam, pés que andam, correm ou simplesmente param. A partir daqui, serão expostos os resultados desse recurso que dispusemos para identificar o que é, para as crianças, a experiência e o significado de jogar. Como bem nos diz Leite (2011): “É pela experiência que entramos na linguagem e é na infância que experimentamos a vida na sua mais plena intensidade, distantes das amarras da razão" (LEITE, 2011, p. 86).

\section{RESULTADO DA ANÁLISE DOS DADOS: O QUE AS CRIANÇAS NOS DISSERAM SOBRE AS FILMAGENS}

Para a análise das filmagens realizadas pelas crianças, além de conversar depois num segundo momento com elas sobre as filmagens realizadas, fizemos uma análise estatística considerando os locais em que ocorriam as filmagens, as atividades filmadas seguidas por suas falas. 
Cerca de $63 \%$ das filmagens realizadas pelas crianças foram fora do contexto de sala de aula. Desses, cerca de $34 \%$ foram nos momentos de recreio, o que segundo as crianças isso aconteceu devido a eles terem mais liberdade de escolha quando estão fora da sala de aula e com seus pares. Para as crianças desse estudo, as práticas lúdicas no ambiente escolar ocorrem em momentos em que elas podem usufruir do movimento corporal para aprimoramento das relações sociais.

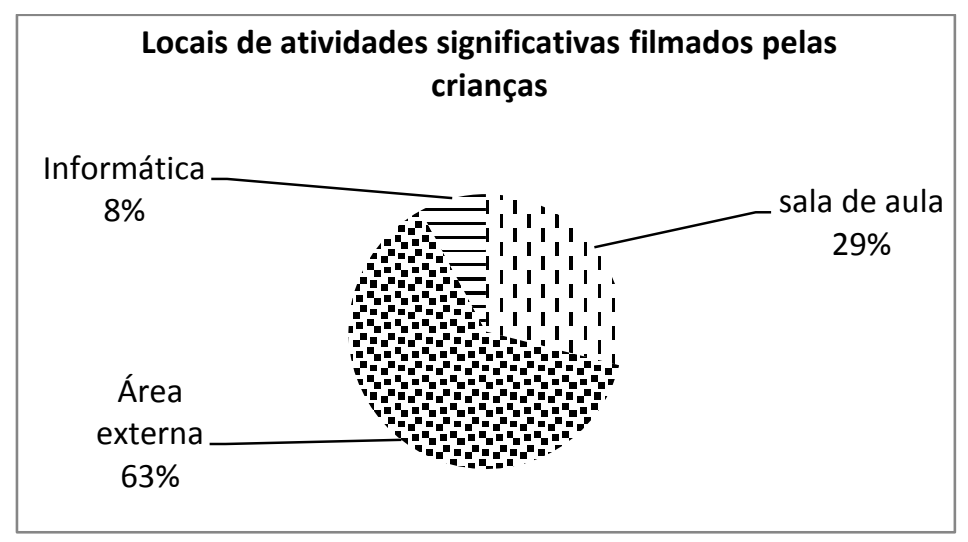

Gráfico. Locais de atividades significativas filmadas pelas crianças

\section{DISCUSSÃO}

Além dos locais filmados pelas crianças, apareceram também várias atividades de caráter lúdico nas filmagens, como o esconde-esconde, brincadeiras de correr, lutinhas, Adoleta, trabalhos em grupos e duplas, jogos da internet, aulas de Educação Física, conversas com os colegas etc.

As crianças consideram que os jogos e as brincadeiras fazem parte de seu processo de ensino e aprendizagem na escola e podem refletir sobre os conhecimentos adquiridos na escola, o que depende da mediação do professor. As filmagens realizadas em sala de aula mostram atividades que supõem uma metodologia diversificada, como trabalhos em grupos e duplas. Isso demonstra através das crianças que participaram dessa pesquisa, que elas valorizam essas práticas pedagógicas e as reconhecem como um diferencial em sua formação escolar.

\section{CONSIDERAÇÕES FINAIS}

Pode-se concluir que, no contexto escolar, as atividades lúdicas podem contribuir de forma relevante para o processo de ensino e aprendizagem das crianças. O furto do lúdico, ocorrido cada vez com mais frequência, pode ser visto também como um furto de aprendizagem, já que o pensamento existente em muitas escolas hoje é de que os jogos e as brincadeiras servem apenas para descanso das atividades intelectuais e como um repositório de energia para as mesmas. 
As práticas lúdicas nas escolas precisam ser vistas com sua especificidade: trata-se de momentos importantes para as crianças dentro das instituições escolares, são capazes de estreitar laços entre crianças e adultos e aprimorar a capacidade social da criança nesse contexto. Porém, ao adotar esse pensamento, precisamos tomar cuidado para não cair na armadilha de enxergarmos o jogo como um "fazer por fazer", pois sua principal característica - a liberdade não significa que o jogo não tenha sentido, mas sim que ele proporciona opções de escolha para as crianças, o que não as impedem de aprenderem no contexto escolar.

\section{REFERÊNCIAS}

CORSARO, W. Sociologia da infância. Porto Alegre: Artmed, 2011, 384p.

DELGADO, A. C. C.; MÜLLER, F. Abordagens etnográficas nas pesquisas com crianças. In: CRUZ, S. H. V. (Org.). A criança Fala. A escuta de crianças em pesquisas. São Paulo, Cortez, 2008, p. 141157.

GOBBI, M. A. Num click: meninos e meninas nas fotografias. In: MARTINS FILHO, A.; PRADO, P. D. (Orgs.). Das pesquisas com crianças à complexidade da infância. Campinas, Autores Associados, 2011, p. $129-157$.

GRAUE, M. E.; WALSH, D. J. Investigação etnográfica com crianças: teorias, métodos e ética. Lisboa: Fundação Calouste Gulbenkian, 2003, 313 p.

LEITE, C. D. P. Infância, experiência e tempo. São Paulo, Cultura Acadêmica, 2011, 166 p.

Crianças na produção de imagens. ComKids.com. Disponível em: http://comkids.com.br/crianças-na-producao-de-imagens/. Acesso em: 17/10/2014.

MARTINS FILHO, A. J. Jeitos de ser crianças: balanço de uma década de pesquisas com crianças apresentadas na Anped. In: MARTINS FILHO, A.; PRADO, P. D. (Orgs.). Das pesquisas com crianças à complexidade da infância. Campinas, Autores Associados, 2011, p. 81 - 106.

SARMENTO, M. J. Conhecer a infância: os desenhos das crianças como produções simbólicas. In: FILHO, A. J. M.; PRADO, P. D. (Orgs.). Das pesquisas com crianças à complexidade da infância. Campinas, Autores Associados, 2011, p. $27-60$. 